\title{
Deposition of Electroless (Ni-P-ZnO) Ternary Alloy for Adhesion Strength on Magnesium (AZ91) Alloy: Effect of Surfactant
}

\author{
Mohd. Imran Ansari and Dineshsingh G. Thakur
}

\begin{abstract}
Magnesium (AZ91) based alloy are being used as structural components in industry because of their high strength-toweight ratio and relatively high stiffness. A shortcoming of AZ91 based alloys is their poor wear and corrosion resistance. Therefore, surface treatment or coatings are needed for protection purpose. Electroless coatings are recognized for their excellent properties and their utilization has witnessed a staggering increase during the last few decades. This present study shows our work on electroless Ni-P$\mathrm{ZnO}$ ternary alloy coatings on AZ91 alloy with influence of anionic surfactant. Results revealed that at an optimum concentration of the surfactant, the coatings obtained a smoother surface and good adhesion as compared to the coating obtained absence of the surfactant. As-deposited substrates were characterized by field emission scanning electron microscopy and energy dispersive X-ray analy sis (FESEM-EDAX).
\end{abstract}

Keywords-Electroless ternary alloy, AZ91 alloy, Adhesion, Surfactant (ALS).

\section{INTRODUCTION}

Electroless composite coating is a kind of surface treatment technology developed on the basis of electroless plating. In recent years, it has won great popularity in preparing composite coatings, which are generally prepared by adding solid particles to the regular electroless $\mathrm{Ni}-\mathrm{P}$ coating solution to achieve deposition of the solid particles and Ni-P matrix. The deposition, to a large extent, improves the mechanical and tribological properties of Ni-P coatings [1-5]. Such coatings with a high corrosion resistance, wear resistance, good adhesion properties and uniform coating thickness have found wide applications in the industries of aviation, aerospace, electronics, petroleum, chemistry, machinery, textiles and automotives [6,7].

Magnesium (Mg) alloy is being used as structural component in various industries because of its low density, high strength-to-weight ratio and relatively high stiffness [8]. On the basis of high specific strength and specific Young's

Mohd. Imran Ansari, Defence Institute of Advanced Technology, Pune, India, E-mail: imransarimech @ gmail.com

Dineshsingh G. Thakur, Defence Institute of Advanced Technology, Pune, India, E-mail: dineshsingh_thakur@yahoo.com modulus, magnesium alloys exhibit better or similar properties than aluminium and many other commercial steels [9]. Electroless coating of ternary alloys on steels exhibits superior corrosion resistance and good wear-ability, and have been well studied. But so far there are not many studies on adhesion properties of electroless coating on $\mathrm{Mg}$ alloys [10-12] which are based on a few patents [13,14]. Furthermore, these studies focused mainly on the effects of processing parameters, such as bath composition, temperature, additives and $\mathrm{pH}$ value, on the deposition. There are no studies focused on the effects of alloy substrate composition and microstructure on adhesion strength properties of coating.

In order to improve the smoothness, brightness and homogeneity of the coatings, along with considerable reduction in surface tension. Surfactants are specifically added in requisite amounts into the bath containing the substrate undergoing the coating process. Surfactant binds or decreases the nickel particles and reduces the formation of hydrogen gas bubbles generated during the plating reaction. This results in uniform deposition or coating with minimal porosity. In low concentration, surfactants exist as isolated molecules. When concentration increases, it forms aggregates called micelles. The concentration at which surfactants begin to form micelles is known as the Critical Micelle Concentration (CMC) [15]. The adhesion between the coating and substrate is an important property of the coating. Electroless deposits sometimes exhibits radial micro cracks and delaminating problem over the substrate surface. Many attempts have been made to find out the effect of surfactants on the roughness of electrodeposited Ni-P coatings. As per studies, addition of anionic Sodium Dodecyl Sulfate (SDS) has shown to have improved the surface morphology, microhardness and surface roughness of the coatings [16,17]. Anionic Ammonium Lauryl Sulfate (ALS) surfactant is a very high-foam surfactant that disrupts the surface tension of water by forming micelles around the polar water molecules and is readily biodegradable. The effect of adding anionic surfactant (ALS) to the ENi-P-ZnO bath composition has not been greatly studied to date. The investigation in this paper highlights the effect of surfactant concentration quantities on adhesion strength properties, surface morphology and elemental analysis on ENi-P-ZnO ternary alloy deposited samples in the chemical bath. 


\section{EXPERIMENT AL DET AILS}

\section{A.Preparation of Sample}

An electroless Ni-P-ZnO ternary alloy coating is deposited on AZ91 magnesium alloy substrate of size $(20 \mathrm{~mm} \times 20 \mathrm{~mm}$ x 6 $\mathrm{mm}$ ) with a pin-hole drilled at the corner (for ease of suspension in the chemical bath). The following preparation of the substrate was carried out prior to conduct of the experiment: AZ91 magnesium alloy (Al 9.2\%, Zn 0.84\%, Mn $0.28 \%$, bal. $\mathrm{Mg}$ (wt $\%)$ ) specimen was mechanically cleaned for removal of corrosion, degreased in acetone, rinsed in $10 \%$ $\mathrm{NaOH}$ at $60{ }^{\circ} \mathrm{C}$ for 05 minutes, $6 \%$ chromic acid $-5 \%$ nitric acid pickling for $45 \mathrm{sec}$, followed by fluoride activation in HF (250 $\mathrm{ml} 40 \% \mathrm{HF}$ per liter) for $10 \mathrm{~min}$. Regular rinsing of specimens is undertaken with distilled water after each step. Specimens were then transferred immediately to the electroless coating solutions. The process treatment of magnesium alloys is always difficult as the substrate is rapidly covered with an oxide film. Hence, the samples should be transferred as quickly as possible between the any two steps of the treatments. After coating, the specimens were again rinsed in distilled water, dried and preserved for characterization.

\section{B. Coating Bath and Operating Conditions}

The composition of basic baths used for deposition had, nickel sulphate as the metal ion source, sodium hypophosphite monohydrate as the reducing agent. The coating solution also contained citric acid and bifluoride, which act as buffers, complexing agents and accelerators. Lead acetate as the stabilizer and brightening agent [18] and operating conditions of ENi-P-ZnO coatings on AZ91 Mg alloy was given in Table I. Various concentrations of the ammonium lauryl sulfate surfactant (ranging from $0.5 \mathrm{~g} / \mathrm{l}$ to $2.0 \mathrm{~g} / \mathrm{l}$ ) were added to the solution before deposition.

T ABLE I

BATH COMPositions AND OPERATING CONDITION OF DEPOSITS

\begin{tabular}{|l|c|}
\hline \multicolumn{1}{|c|}{ Composition and process condition } & $\begin{array}{c}\text { Bath } \\
\text { quantity }\end{array}$ \\
\hline $\mathrm{NiSO}_{4} \times 6 \mathrm{H}_{2} \mathrm{O}(\mathrm{g} / \mathrm{l})$ & 18 \\
\hline $\mathrm{NaH}_{2} \mathrm{PO}_{2} \times \mathrm{H}_{2} \mathrm{O}(\mathrm{g} / \mathrm{l})$ & 22 \\
\hline Citric acid monohydrate $(\mathrm{g} / \mathrm{l})$ & 5 \\
\hline Ammonium bifluoride $(\mathrm{g} / \mathrm{l})$ & 8 \\
\hline Hydrofluoric acid, $\mathrm{HF}(40 \% \mathrm{~V} / \mathrm{V})(\mathrm{ml} / \mathrm{l})$ & 12 \\
\hline Ammonium lauryl sulfate $(\mathrm{g} / \mathrm{l})$ & $0.0-2.0$ \\
\hline pH (NaOH) & $6.5 \pm 0.2$ \\
\hline Temperature $\left({ }^{\circ} \mathrm{C}\right)$ & $82 \pm 1$ \\
\hline Coating duration $(\mathrm{min})$ & 120 \\
\hline
\end{tabular}

C. Surface Characterization of Deposits

A field emission scanning electron microscopy (FESEM) [Model: igma, Carl Ziess] was used for the observations of the surface morphology of deposits obtained from solutions containing surfactant added. The interfacial adhesion between coating and the substrates were tested as per VDI 3198 norms $[19,20]$ which recommend a standard Rockwell hardness tester fitted with a Rockwell 'C'-type diamond cone indenter with an applied load of $150 \mathrm{~kg}$.

\section{RESULT S AND DISCUSSION}

\section{A.Surface Morphology and Characterization Without and} With Surfactant

Surface morphology of the deposits was thoroughly examined using Field Emission Scanning Electron Microscopy (FESEM). The FESEM morphology of ENi-P deposits with different concentrations of ALS are as shown in figure 1. It is observed that in the ENi-P deposit without surfactant, the dispersion of nickel particles is considerably mild [fig. 1(a) refers] as compared to the deposit with surfactant. With addition of surfactant, the amount of Ni particle deposition onto the substrate is found to have increased significantly. The same it attributable to the surfactant property, that ensures ease of dispersion of particles in the bath, along with decrease in surface tension in the liquid. The same can be easily visualized from figure 1(b-e) which shows that there is a fine and uniform deposition along with smooth surface that is achieved as the concentration of ALS surfactant is increased from $0.5 \mathrm{~g} / \mathrm{l}$ to $2.0 \mathrm{~g} / \mathrm{l}$.

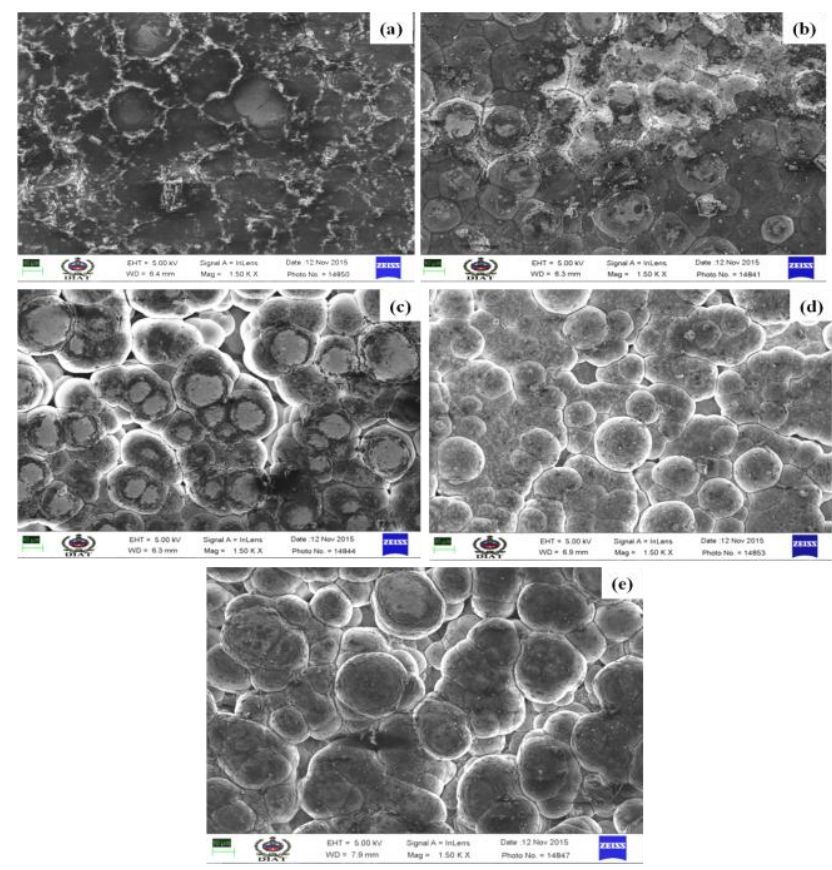

Fig. 1 FESEM morphologies (1.5 KX) of as-deposited condition electroless deposit with various ALS concentrations; (a) without surfactant, (b) $0.5 \mathrm{~g} / \mathrm{l}$, (c) $1 \mathrm{~g} / \mathrm{l}$, (d) $1.5 \mathrm{~g} / \mathrm{l}$ and (e) $2 \mathrm{~g} / \mathrm{l}$

When ALS is added into bath composition, the phosphorus content was observed to gradually increase from $7 \%$ to $9 \%$. However, on further increasing the ALS concentration, the phosphorus content jumped sharply to $11 \%$, thereby reducing 
the coating microhardness. Figure 2 shows the variation of phosphorus content versus ALS concentration. Hence, there is a vast improvement in mechanical properties of the coatings done in the presence of ALS surfactant.

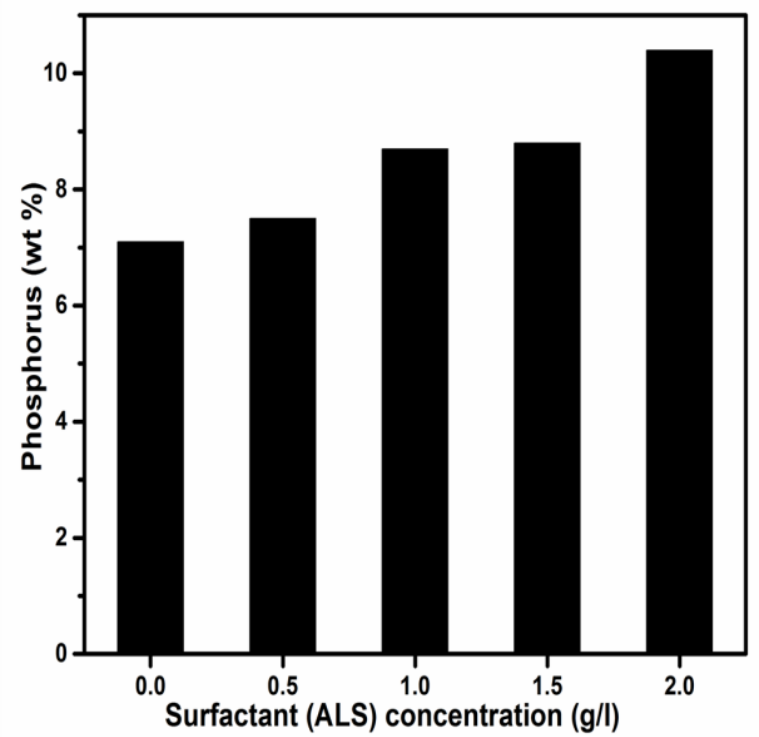

Fig. 2 Variation of phosphorus content on electroless deposition with various ALS surfactant concentrations; (a) without surfactant, (b) 0.5 $\mathrm{g} / \mathrm{l}$, (c) $1 \mathrm{~g} / \mathrm{l}$, (d) $1.5 \mathrm{~g} / \mathrm{l}$ and (e) $2 \mathrm{~g} / \mathrm{l}$

\section{B. Effect of Surfactant on the Adhesion}

Figure 3 illustrates the optical micrograph of electroless deposited substrates. The interfacial properties of deposited particles and the substrate surface are modified by the surfactants, which directly influences the adhesion. Figure 3(a) shows the optical image of electroless deposited substrate in the absence of surfactant. A better interfacial adhesion is observed but a large number of radial micro-cracks can be seen. Figure 3(b) depicts the optical image of electroless deposited substrates in the presence of surfactant at the concentration of $1.5 \mathrm{~g} / \mathrm{l}$, which is the CMC of ALS. The presence of surfactant in the bath solution indicates a better adhesion to the substrate surface. This is because of the fact that surface of the substrate adsorbs the hydrophilic part of surfactants along with the fine nickel particles produced in the bath and a monolayer is formed by the hydrophobic part of surfactants which prevents the flotation of nickel particles to the top surface in the bath solution.
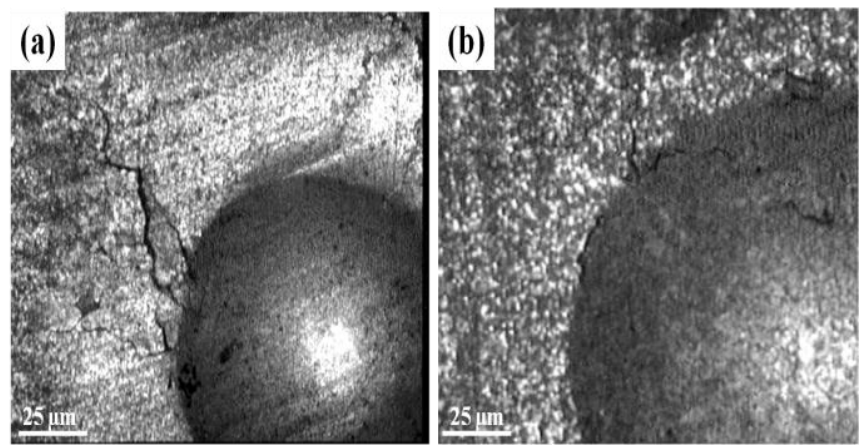

Fig. 3 Optical micrographs (500x) showing interfacial adhesion of electroless deposited substrates (a) without surfactant; (b) addition of surfactant at $1.5 \mathrm{~g} / \mathrm{l}$ concentration

\section{CONCLUSION}

On the basis of experimental investigations undertaken by addition of anionic surfactant (ALS) in a chemical bath composition of the ENi-P-ZnO ternary alloy, to obtain deposit on AZ91 magnesium alloy substrate, it was observed that there was a significant improvement in the adhesion strength properties of the ternary alloy deposited layers. The following conclusions are drawn on the basis of experimental investigations:-

(i) Addition of ALS surfactant resulted in uniform dispersion of fine nickel particles over the surface of substrate, thereby resulting in smooth surface finish of the deposited layers.

(ii) The Rockwell $\mathrm{C}$ adhesion test showed the adhesion of as-deposited Ni-P-ZnO coating in the presence of surfactant at $1.5 \mathrm{~g} / 1$ concentration on AZ91 alloy substrate is sufficient with few micro-cracks. Multiple cracks with few delamination and flanking failures were observed in the absence of surfactant, however the adherence of the coating is adequate and considered as suitable and not cause for failure.

Thus, addition of ALS surfactant in ENi-P-ZnO bath results in improved surface coating along with enhanced adhesion properties. This greatly widens the scope of applications of the resulting coating.

\section{ACKNOWLEDGMENT}

The authors would like to thank the Defence Institute of Advanced Technology (DU), Ministry of Defence, Pune, Maharashtra, India for encouragement and support.

\section{REFERENCES}

[1] A. Grosjean, M. Rezrazi, J. Takadoum, and P. Bercot, "Hardness, friction and wear characteristics of nickel-SiC electroless composite deposits," Surf. Coat. Technol. Vol. 137, pp. 92-96, March 2001.

[2] I. Apachitei, F.D. Tichelaar, J. Duszcyk, and L. Katgerman, "The effect of heta treatment on the structure and abrasive wear resistance of autocatalytic NiP and NiP-SiC coatings," Surf. Coat. Technol. Vol. 149, pp. 263-278, Jan. 2002.

[3] M.I. Ansari, and D.G. Thakur, "Effect of bath agitation on surface properties and corrosion behaviour of ENi-P coatings along with annealing temperature," Eng. Sci. Technol. Int. J., vol. 19, pp. 2094-2099, Dec. 2016. 
[4] Ming-Der Ger, and Bing Joe Hwang, "Effect of surfactants on codeposition of PTFE particles with electroless Ni-P coating," Mater. Chem. Phys., vol. 76, pp. 38-45, July 2001.

[5] M.I. Ansari, and D.G. Thakur, "Study of mechanical properties of electroless nickel-phosphorus coatings with influence of surfactant on AZ91 magnesium alloy," Adv. Eng. Forum, vol. 15, pp. 56-63, Feb. 2016.

[6] J.G. Jin, S.K. Lee, and Y.H. Kim, "Adhesion improvement of electroless plated Ni layer by ultrasonic agitation during zincating process," Thin Solid Film., vol. 466, pp. 272-278, Nov. 2004.

[7] S. Julka, M.I. Ansari, and D.G. Thakur, "Effect of pH on mechanical, physical and tribological properties of electroless Ni$\mathrm{P}-\mathrm{Al}_{2} \mathrm{O}_{3}$ composite deposit for marine applications," J. Marine Sci. Appl., vol. 15, pp. 484-492, Dec. 2016.

[8] R. Hu, Y. Su, H. Liu, J. Cheng, X. Yang, and Z. Shao, "The effect of adding corrosion inhibitors into an electroless nickel plating bath for magnesium alloy," J. Mater. Eng. Perf., vol. 25, pp. 45304536, Oct. 2015.

[9] Abdel-Wahab El-Morsy, "Dry sliding wear behavior of hot deformed magnesium AZ61 alloy as influenced by the sliding conditions," Mater. Sci. Eng. A., vol. 473, pp. 330-335, Jan. 2008.

[10] G.E. Shahin, Corrosion and wear resistance of electroless nickel on magnesium alloys. Magnesium Technology 2002, TMS Annual Meeting, Seattle, WA, United States: The Minerals, Metals \& Materials Society, 2002.

[11] A.K. Sharma, M.R. Suresh, H. Bhojraj, H. Narayanamurthy, and R.P. Sahu, "Electroless Nickel Plating on Magnesium Alloy," Metal Finish., vol. 96, pp. 10-16, Mar. 1998.

[12] W.A. Fairweather, "Electroless nickel plating of magnesium," Trans. Inst. Metal Finish., vol. 75, pp. 113-117, May 1997.

[13] P. Budininkas, Improvements in and relating to Chemical Nickel Plating of Magnesium and its Alloy. US9J2956, United States Patent Office, USA, 1962.

[14] M.I. Ansari, D.G. Thakur, "A high performance of ENi-P coatings on mechanical and tribological properties with influence of bath $\mathrm{pH}$ on AZ91 magnesium alloy," J. Fail. Anal. Preven., vol. 17, pp. 100-106, Feb. 2017.

[15] D.J. Shaw, Introduction to colloid and surface chemistry. $2^{\text {nd }}$ edn., Woburn, MA, Butterworth, 1978.

[16] R. Elansezhian, B.Ramamoorthy, and P.K. Nair, "Effect of surfactants on the mechanical properties of electroless (Ni-P) coating," Surf. Coat. Technol., vol. 203, pp. 709-712, Dec. 2008.

[17] J. Sudagar, J.S. Lian, Q. Jiang, Z.H. Jiang, G.Y. Li, and R. Elansezhian, "The performance of surfactant on the surface characteristics of electroless nickel coating on magnesium alloy," Prog. Org. Coat., vol. 74, pp. 788-793, Aug. 2012.

[18] M.I. Ansari, and D.G. Thakur, "Influence of surfactant: Using electroless ternary nanocomposite coatings to enhance the surface properties on AZ91 magnesium alloy," Surf Interf., vol. 7, pp. 2028, June 2017.

[19] Verein Deutsher Ingenieure Normen, VDI 3198, VDI-Verlag, Dusseldorf, 1991.

[20] S. Karthikeyan, and L. Vijayaraghavan, "Investigation of the surface properties of heat treated electroless Ni-P coating," Trans. $I M F$., vol. 94, pp. 265-273, Sep. 2016. 